\title{
Rail Surface Defect Detection and Analysis Using Multi-Channel Eddy Current Method Based Algorithm for Defect Evaluation
}

\author{
Jeong Won Park ${ }^{1} \cdot$ Taek Gyu Lee $^{2}$. In Chul Back ${ }^{3}$ Sang Jun Park ${ }^{4}$. Jong Min Seo ${ }^{3}$. Won Jae Choi ${ }^{1}$ Se Gon Kwon ${ }^{3}$
}

Received: 12 April 2021 / Accepted: 11 August 2021 / Published online: 9 September 2021

(c) The Author(s) 2021

\begin{abstract}
The railroad rail support trains and contributes to their operation. Internal and surface defects occur on the rail due to various combinations of causes including fatigue loading and cyclic tension and compression among others from the deterioration of the rail along with the temperature differences of seasonal changes. Surface defects such as head check, shelling, and squats start out in the rail head and become internal defects due to poor maintenance, ultimately resulting in rail failure. In order to prevent rail failure, it is important that defects are identified through nondestructive evaluation (NDE) in advance and to carry out maintenance techniques including grinding. NDE methods include MFL, EMAT, and ECT, and among these, the ECT method is a representative method with excellent detection sensitivity that nondestructively inspects metal surfaces such as rails and pipes using an electromagnetic field. Also, since the defect signal is obtained as an electrical signal, the depth, length, and width of defects can be assessed using a defect evaluation algorithm. This study investigated the field applicability and future practical use of the 16 channel eddy current testing equipment and defect evaluation algorithm developed in this study. Therefore, the field applicability of the equipment and defect evaluation algorithm was investigated through the detection of artificial defects with varying size and depth. Afterwards, future practical use was evaluated by inspection of areas of rail that are in use and with naturally occurring surface defects and analysis of their size (length, width), depth, and phenomena.
\end{abstract}

Keywords Rail surface defect $\cdot$ Eddy current testing $\cdot$ Natural defect $\cdot$ Defect sizing $\cdot$ Multi-channel eddy current equipment

\section{Introduction}

With rapid advancement in industries related to transportation, the deterioration of existing infrastructure such as railways and roads has been pointed out as a safety issue. In particular, rails are composed of artificial structures including the sleeper, roadbed, and ballast, which distribute the loading applied on the rail, and have the important role of supporting trains that are responsible for the transportation of numerous people and goods [1-3]. Therefore, damage on a national scale including human casualties and economic loss can occur when the safety of the rail, the most important component of the track, is not guaranteed [2-4]. Defects of the rail are largely categorized into internal and surface defects, and factors that can cause surface defects include degradation, temperature differences due to seasonal changes, fatigue loading due to the passing tonnage of trains, and contact with foreign objects (ballast flying, snow and ice, etc.) between the wheel and rail during train operation $[5,6]$ Due to these factors, surface defects such as squats, 
shelling, and head check occur, and research is actively carried out on the prevention of accidents such as train derailment caused by rail rupture using nondestructive and maintenance methods including grinding and overlay welding [5-7] Various nondestructive techniques are studied in order to establish maintenance standards for the early detection of surface defects, and nondestructive methods used on rails in the field include ultrasonic testing (UT) and eddy current testing (ECT). As UT is a contact type method that is mainly used to detect internal defects, the non-contact type ECT is appropriate for the inspection of rail surface defects. In ECT, alternating current is applied to a coil sensor to produce a magnetic field, which produces an eddy current due to electromagnetic induction as the surface of the test specimen is approached $[8,9]$. The eddy current distributed on the test specimen surface is established in the opposite direction of the magnetic field produced by the coil sensor, and thus when defects or nonuniform areas exist, the difference in the magnetic fields produced by the coil and the test surface results in variations in the impedance and electromotive force [10-12]. Therefore, information on defects such whether defects exist and their sizes and depths can be obtained through the electrical signal variation such as the impedance between the test surface and the coil sensor [13, 14]. Eddy current equipment for rail inspection today are entirely imported from overseas, and therefore repairs in the case of malfunctions are costly and time consuming. Thus, not only are inspections unable to take place during repairs, but users lacking expert knowledge of eddy currents have difficulty in acquiring accurate data regarding defects using the inspection program that only expresses results using 1-dimensional signals such as the Lissajous plane, phase, and amplitude along with the complicated defect evaluation program. Also, there is the inconvenience of having to move the data after completion of the inspection to a dedicated analysis computer for characterization of the presence of defects and their sizes. In the case of the existing inspection equipment, four sensors are arranged vertically and the angle of each sensor is adjusted by the user to set the equipment at the desired inspection location of the rail head; if the defects are not located within the inspection range, detection is thus difficult and the defect detection rate decreases. Therefore, a 16 channel eddy current inspection device was developed, which uses 16 sensors to inspect the entirely of the rail head, and user convenience was taken into consideration, providing real-time $2 \mathrm{D}$ images during the inspection to determine whether defects are present along with 3D images of the inspection location to obtain accurate information regarding the shapes and sizes of the defects. In this study, the 16 channel eddy current inspection equipment was used to verify the field applicability of the equipment through an analysis of the defect location based on the 2D and 3D inspection images of artificial defects of varying sizes and depths and through the developed defect evaluation algorithm for defect size and depth analysis. Furthermore, practical use of the equipment was shown for three natural defects on rail that is currently in operation.

\section{Experimental Setup}

\subsection{Setup of the 16 Channel Eddy Current Inspection Equipment and Experiment Method}

Figure 1 shows the multi-channel eddy current inspection equipment, which is placed on top of the rail and scans the rail surface as the operator pushes the equipment forward. The equipment is composed of the eddy current system, 16 channel sensor jig, inspection and analysis program, and main power system. The eddy current system inputs the voltage and frequency necessary for the operation of the sensors and performs processing and storage of the acquired signal and the encoder signal. The inspection and analysis program is composed of calibration, 2D, amplitude, Lissajous plane, 3D, and defect sizing. The $2 \mathrm{D}$ image, amplitude, and Lissajous plane are displayed in real-time during the inspection, and the location and approximate size of the defect can be identified. Accurate information on the defect can be obtained from the estimated defect length, width, and depth results through the 3D image and defect sizing, which utilize the location of defect detection and data after completion of the inspection. The 16 channel sensor jig has four wheels that act as a guide along the side of the rail for stability when the equipment is placed on top of the rail, and each sensor has a suspension system to maintain uniform lift-off when the equipment is placed on top of a nonuniform rail surface due to deterioration. The sensor arrangement is $4 * 4$ and ceramic pads of the same $0.5 \mathrm{~mm}$ thickness were attached at the bottom of the sensors to prevent damage to the sensors. The main power system provides power to the eddy current system and display panel.

\subsubsection{The 16 Channel Eddy Current Sensor}

Figure 2a shows the sensors of the eddy current inspection equipment. As can be seen in the figure, the sensors are divided into two groups with eight channels each and they are connected to the eddy current system. Each sensor was manufactured as connector types for convenient repair. Figure $2 b$ shows the plus $(+)$ point sensor, which is a differential sensor fabricated in a plus $(+)$ shape where each layer is wound in a crisscrossing manner. The differential sensor is composed of two receiving sensors, and each received signal is simultaneously affected and cancelled out, resulting in the output signal level of 0 . Hence, they are not significantly affected by lift-off and noise, and 


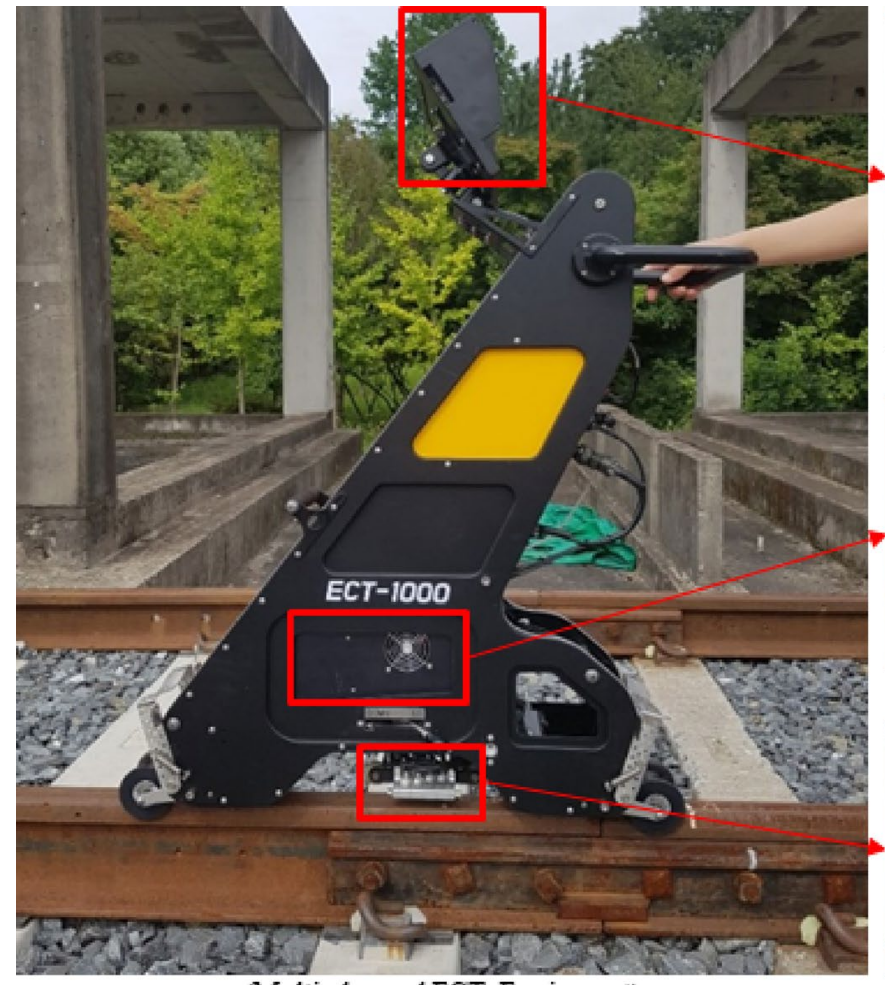

$<$ Multi channel ECT Equipment>

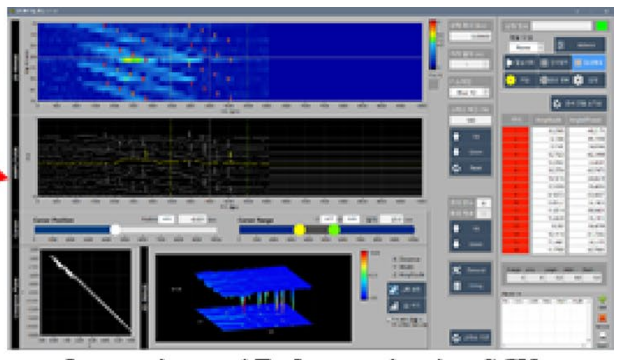

Inspection and Defect evaluation S/W >
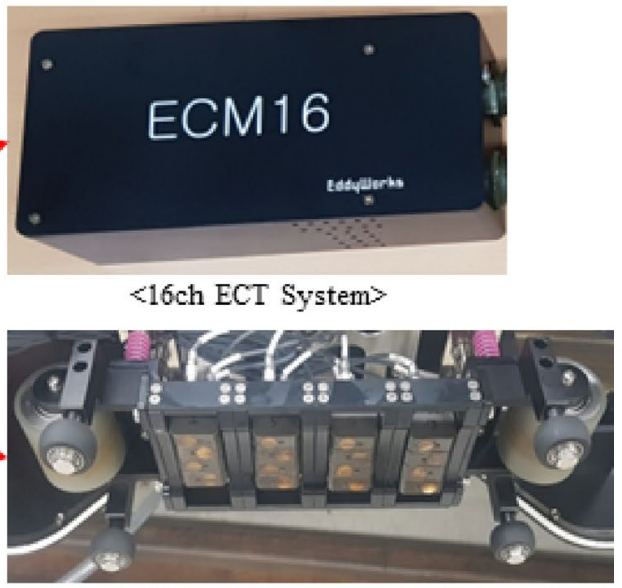

$<16 \mathrm{ch}$ ECT Sensors and Jig>

Fig. 1 Configuration of the multi-channel eddy current equipment

Fig. 2 Multi-channel eddy current sensor: a $16 \mathrm{ch}$ eddy current sensor and $\mathbf{b}$ plus (+) point sensor

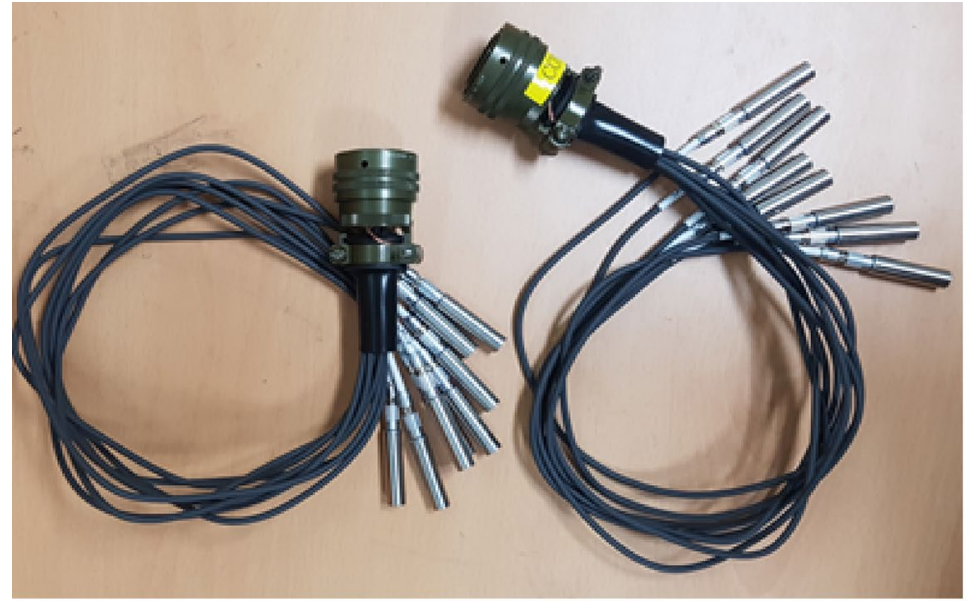

(a)

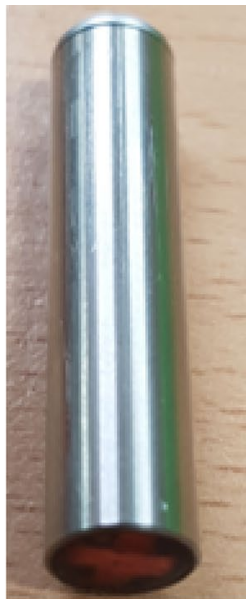

(b) defect detection in the circumferential and axial directions are possible $[15,16]$. The sensors have an external diameter of $8 \mathrm{~mm}$, wire diameter of $0.1 \mathrm{~mm}$, total of four layers, operating frequency of $300 \mathrm{kHz}$, applied voltage of $7 \mathrm{Vpp}$, and lift-off of $1 \mathrm{~mm}$. Additionally, the intervals between the left and right sensors were $0.16 \mathrm{~mm}$ and the intervals between the forward and behind sensors were $3 \mathrm{~mm}$.

\subsubsection{Experiment Configuration}

Figure 3 shows a schematic diagram of the process all the way to the defect evaluation using the data obtained from the eddy current system from scanning the rail. Excitation of the ECT sensor is carried out through the frequency and voltage inputted from the $16 \mathrm{ch}$ ECT system. The sensor 


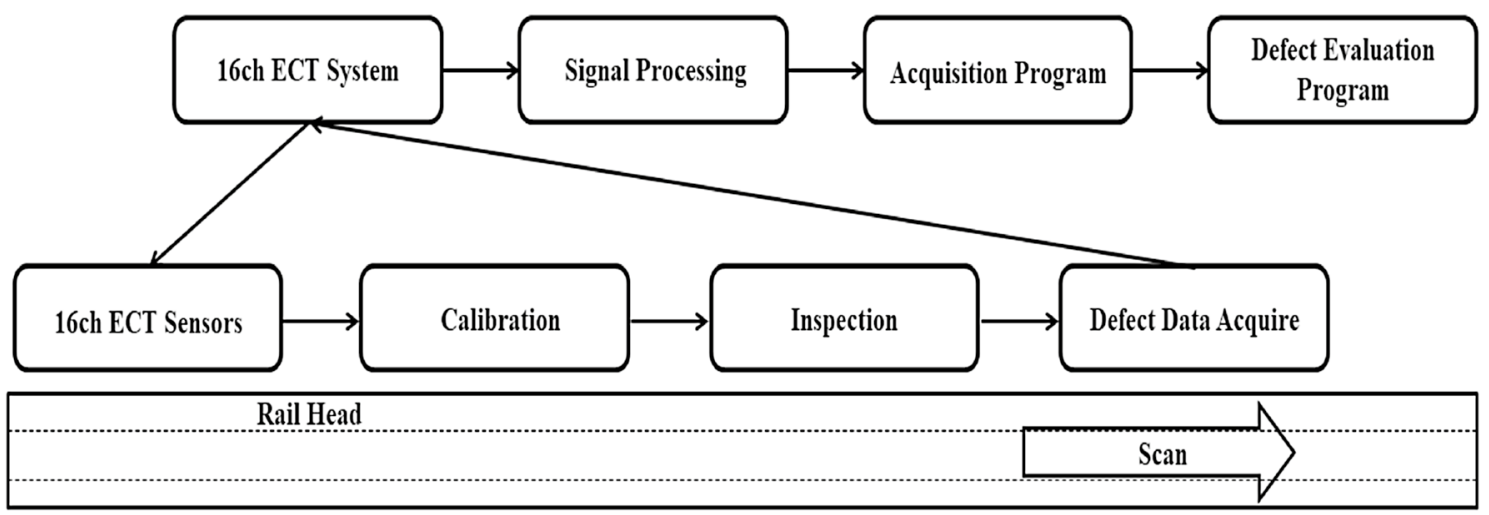

Fig. 3 Schematic of the ECT system

produces a magnetic field using the excitation, and after calibration to maintain uniform sensitivity, the target rail is scanned for inspection and data are acquired through the ECT system. The acquired raw data undergo signal processing to obtain information regarding defects using the $16 \mathrm{ch}$ signal, 2D image, and Lissajous plane, which appear in real time through the acquisition program. Also, the sizing of the defect is conducted including the length, width, and depth of the defect through the 3D image and defect evaluation algorithm for accurate defect analysis. Approximate sizing of defects during use is possible in the development equipment, and for precise analysis, it is possible through the developed defect evaluation algorithm program after defect detection is completed.

\subsubsection{Calibration of the $16 \mathrm{ch}$ ECT Sensors}

Figure 4 shows the calibration method of the 16ch eddy current sensor and a slit defect of $1 \mathrm{~mm}$ width and $3 \mathrm{~mm}$ depth was made cutting through in the direction transverse of the rail head surface. Before calibration, defects appear like the sensor arrangement, and since the plus point sensor is made by hand, the 16 resistors are not the same, so there is a difference in sensitivity. Therefore, by using the balancing and calibration functions in the program, the sensitivity of the sensor is made the same. After calibration, it appears the same as the shape of the defect, and it can be seen that the sensitivity of the sensor is the same with the red line in the middle. Calibration test specimens of varying rail sizes $(50 \mathrm{~K}, 60 \mathrm{~K}$, UIC60) were prepared and data were recorded after calibration. Thus, calibration does not have to be performed for every inspection as the calibration data for the corresponding rail that are stored in advance can be loaded and used.

\subsection{Test Specimens with Artificial and Natural Defects}

In order to check the applicability of the defect evaluation algorithm, 8 artificial defects in the shape of a rectangle with different sizes and depths were manufactured on the UIC60 rail used in high-speed craft as shown in Fig. 5a. As shown in Fig. 5b, the four defects on the left had the same depth but varying vertical and horizontal dimensions while the four defects on the right had the same dimensions but varying depths that increases in $2 \mathrm{~mm}$ intervals. The defects were fabricated at locations at least $360 \mathrm{~mm}$ from the edges on both sides in order to prevent the edge effect. The defects were distanced $50 \mathrm{~mm}$ apart from each other for accurate analysis of the detection signal. The test specimens with

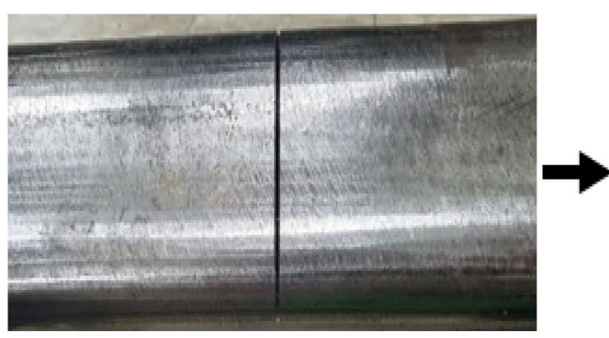

Calibration specimen

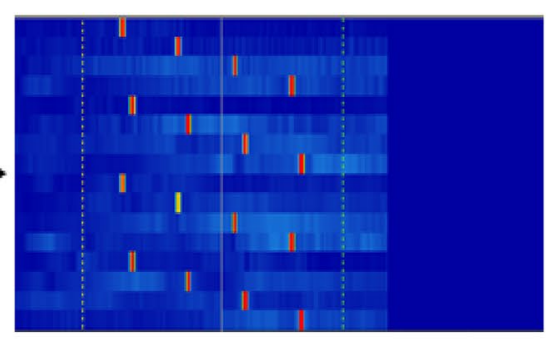

Before calibration

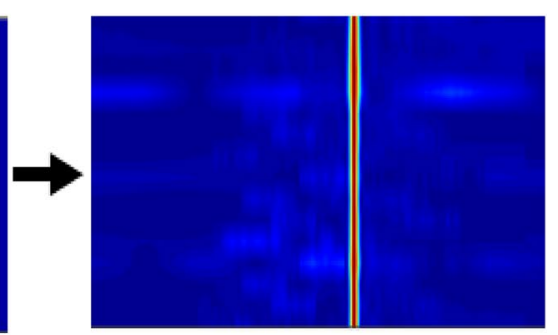

After calibration

Fig. 4 Calibration method of 16ch ECT sensors 


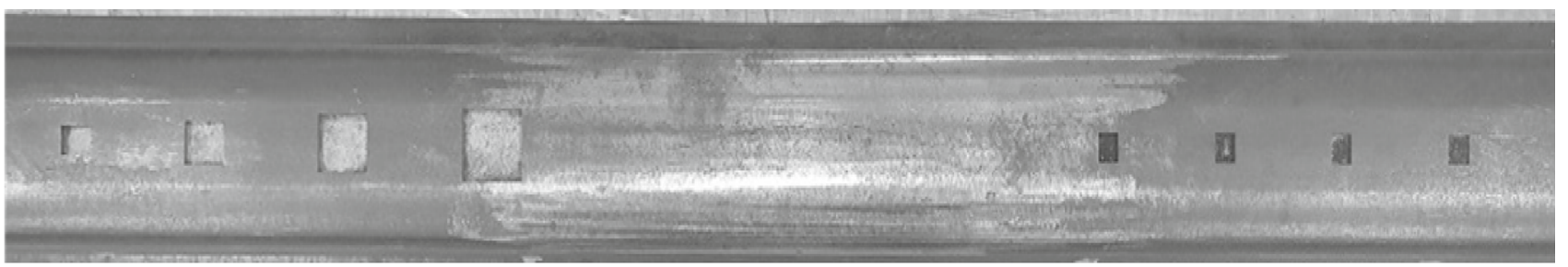

(a)
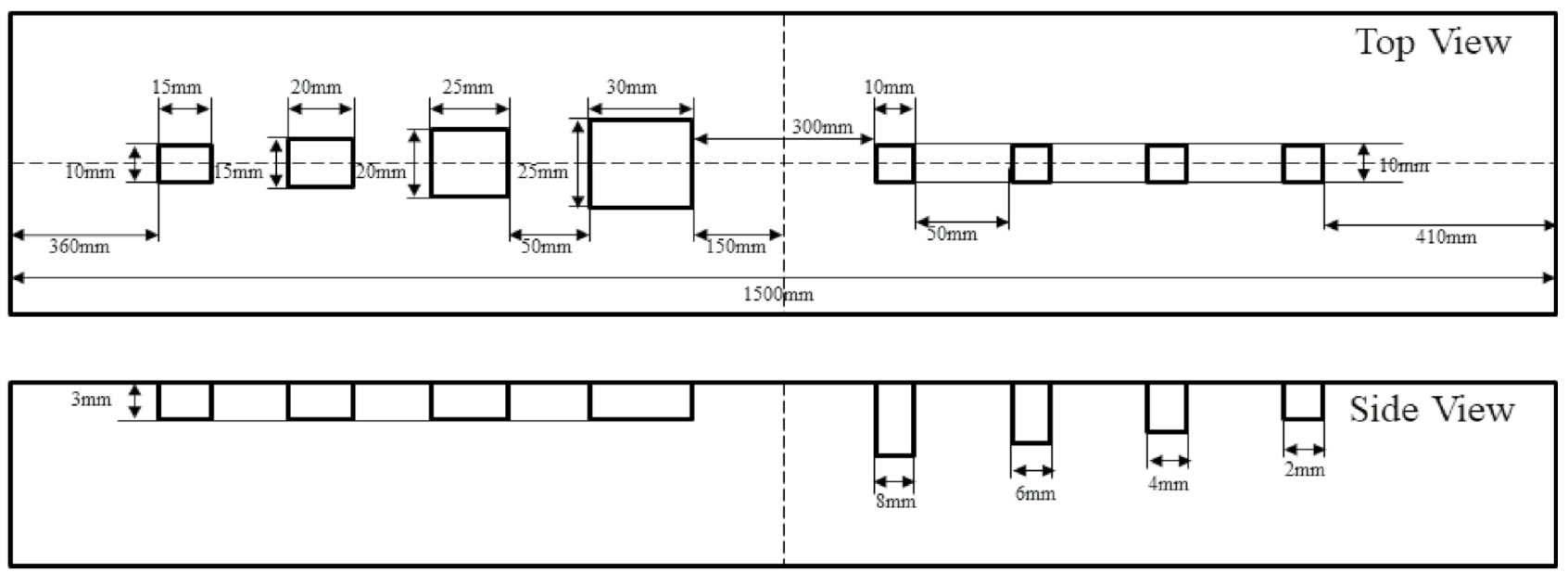

(b)

Fig. 5 Squats artificial defects (UIC60): $\mathbf{a}$ artificial defects picture and $\mathbf{b}$ defect size

natural defects were obtained from detection of defects on the rail surface of a high speed line in operation and the defect type is shelling. Shelling occurs due to the penetration of foreign substances between the wheel and rail during train operation or impact of the rail surface by hard objects like ballast about the rail [17]. Therefore, since the surface where a portion of the rail broke off is not smooth and takes on a geometric shape, the defect length and width can be measured but measuring the depth is difficult, and therefore the length, width, and depth of the defect were obtained using the radiographic test (RT) method.

\section{Experiment Results and Discussion}

\subsection{Artificial Defect Sizing}

Figure $6 \mathrm{a}-\mathrm{d}$ are 2D and 3D images of artificial defect specimens. Blue is the part with no defects, and parts with a color other than blue are defective. Figure $6 \mathrm{a}$ is a 2D image of a defect with different widths and lengths. It was confirmed that as the size of the defect increased, the area of the color representing the defect increased. In Fig. 6b, the 3D image of Fig. 6a shows that the center and lower part of the defect have similar amplitude values, but the upper edge amplitude values are relatively large. The reason is that although it was machined to a uniform depth of $3 \mathrm{~mm}$, an artificial defect was made on the rail that was used, so the lower part of the head wears more than the upper part, and the amplitude is larger at the lower edge part. That is, the difference in amplitude occurred due to the lift-off difference between the sensor at the top and the center because the sensor did not make perfect contact with the lower curvature. Figure $6 \mathrm{c}$ is a $2 \mathrm{D}$ image with increasing depth, and the length and width of the defect are the same. Therefore, the size of all 2D images appeared to be the same. When looking at the 3D image of Fig. $6 \mathrm{~d}$ to confirm the depth of the defect, the amplitude of the amplitude decreased as the depth decreased. When the results of 8 artificial defects of different lengths, widths, and depths were checked in 2D and 3D images, they were all able to be distinguished and the possibility of field application of the developed equipment could be determined.

\subsubsection{Defect Dimension Sizing}

Table 1 shows the length and width sizing results of the four defects of varying sizes through measurements repeated three times, and the values of Table 1 are plotted in Fig. 7a and b. As can be observed in Fig. 7a; Table 1, the average estimated lengths of $15,20,25$, and $30 \mathrm{~mm}$ were approximately $15.29,20.12,25.1$, and $29.92 \mathrm{~mm}$, respectively, and thus the errors were about +0.05 and $-0.12 \mathrm{~mm}$ 


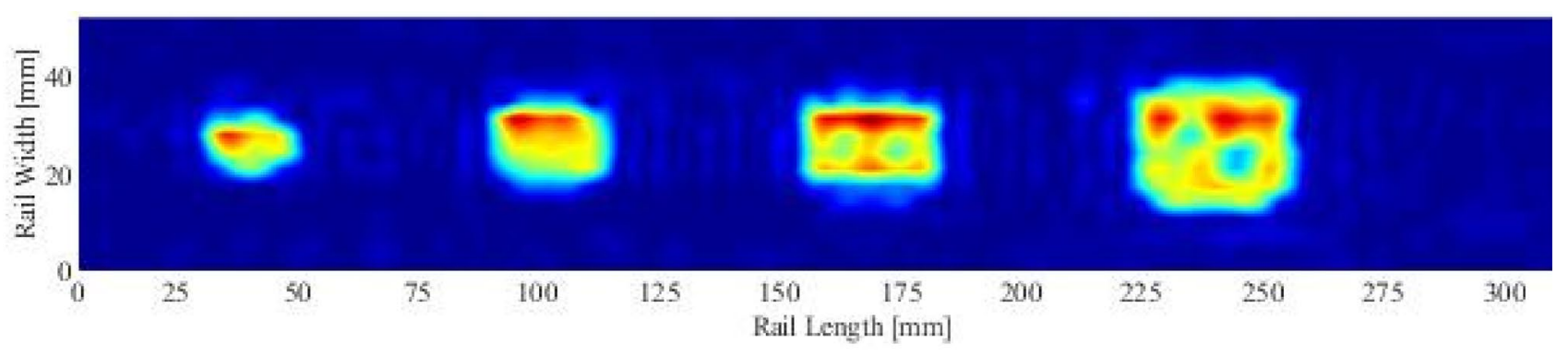

(a)

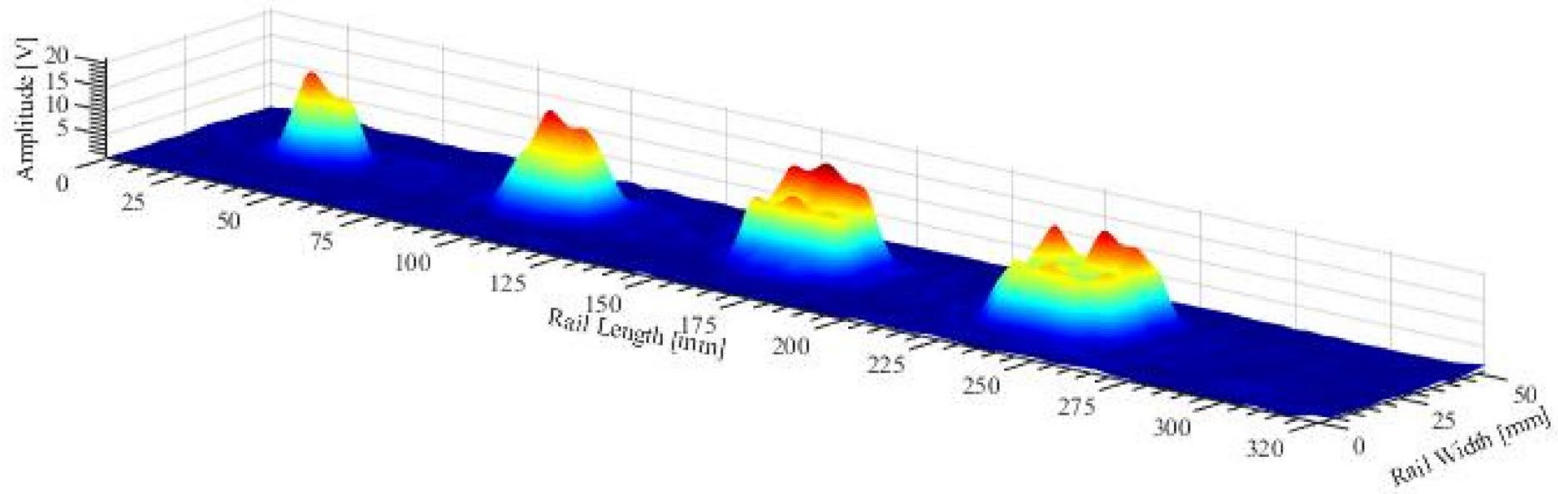

(b)

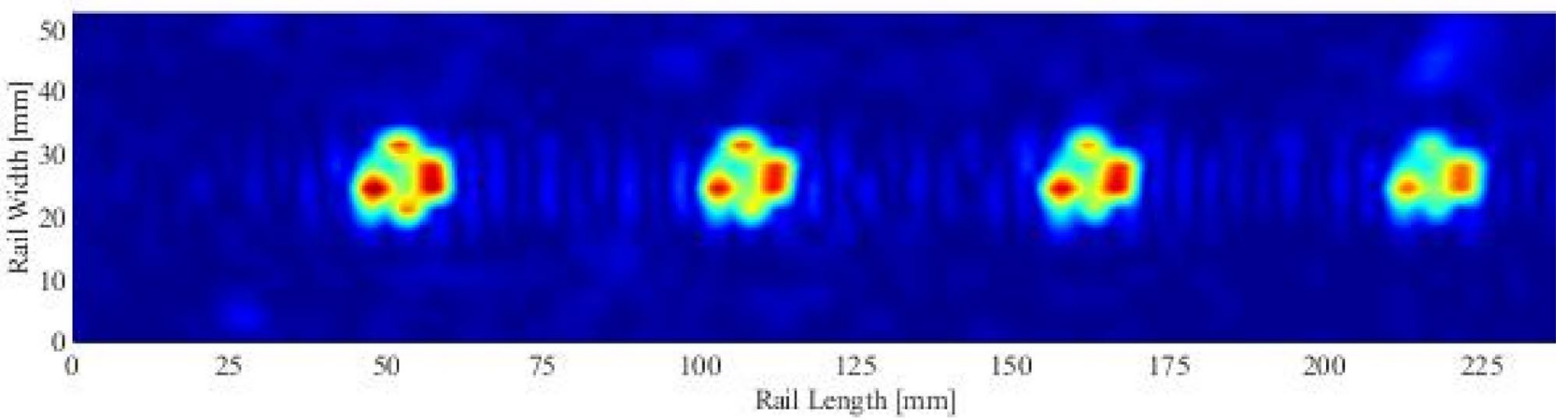

(c)

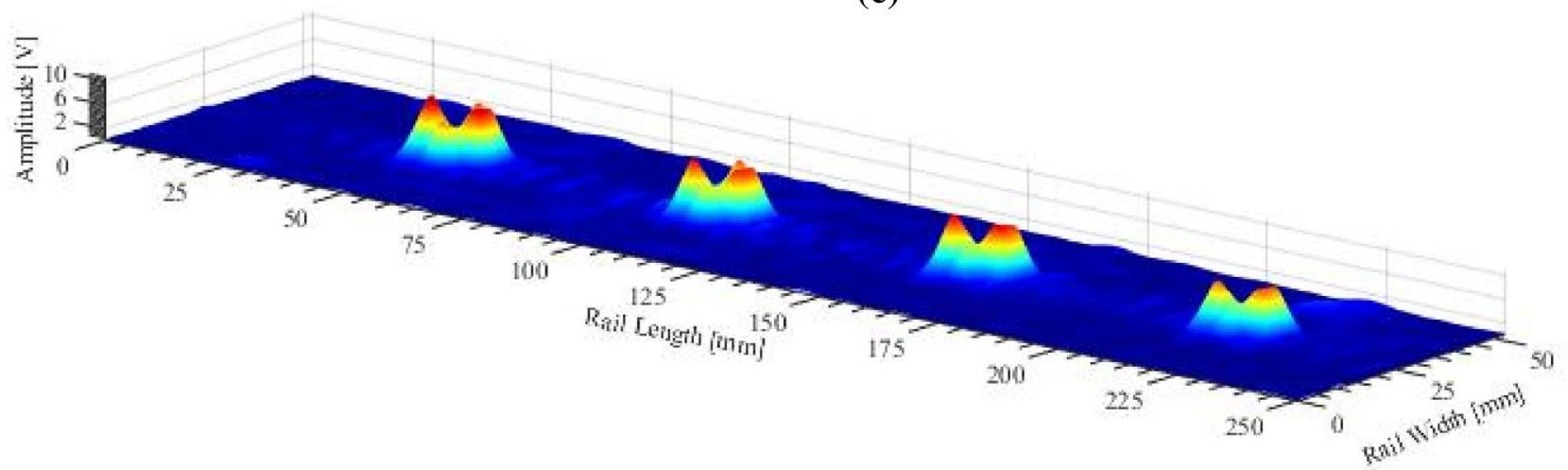

(d)

Fig. 6 Artificial defect 2D and 3D image: a 2D image of the size variation defects and $\mathbf{b}$ 3D image of the size variation defects and $\mathbf{c}$ 2D image of the depth variation defects and $\mathbf{d} 3 \mathrm{D}$ image of the depth variation defects 
Table 1 Defect sizing

\begin{tabular}{lllll}
\hline Category & $\begin{array}{l}\text { Actual size } \\
{[\mathrm{mm}]}\end{array}$ & \multicolumn{3}{l}{ Estimate size $[\mathrm{mm}]$} \\
\cline { 3 - 5 } & & $1 \mathrm{st}$ & 2nd & 3rd \\
\hline \multirow{2}{*}{ Length } & 15 & 15.5 & 14.88 & 15.5 \\
& 20 & 19.94 & 19.94 & 20.5 \\
& 25 & 24.92 & 25.5 & 24.88 \\
& 30 & 29.88 & 29.94 & 29.94 \\
Width & 10 & 10.37 & 10.46 & 10.5 \\
& 15 & 15.5 & 15.5 & 15.37 \\
& 20 & 19.54 & 20.5 & 20.46 \\
& 25 & 25.46 & 25.37 & 25.5 \\
\hline
\end{tabular}

for $15 \mathrm{~mm},+0.5$ and $-0.06 \mathrm{~mm}$ for $20 \mathrm{~mm},+0.5$ and $-0.12 \mathrm{~mm}$ for $25 \mathrm{~mm}$, and $-0.12 \mathrm{~mm}$ for $30 \mathrm{~mm}$. As shown in Fig. 7b; Table 1, the average estimated widths of $10,15,20$, and $25 \mathrm{~mm}$ were approximately $10.44,15.45$, 20.16 , and $25.44 \mathrm{~mm}$, respectively, and thus the errors were about $+0.5 \mathrm{~mm}$ for $10 \mathrm{~mm},+0.5 \mathrm{~mm}$ for $15 \mathrm{~mm}, \pm 0.5 \mathrm{~mm}$ for $20 \mathrm{~mm}$, and $+0.5 \mathrm{~mm}$ for $25 \mathrm{~mm}$. Therefore, the estimate results for the four defects with regard to the repeated measurements of length and width were approximately +0.5 and $-0.12 \mathrm{~mm}$ for length and $\pm 0.5 \mathrm{~mm}$ for width, and hence the defect error range where the length and width both increased was around $\pm 0.5 \mathrm{~mm}$.
Fig. 7 Estimate sizing: a Length sizing and $\mathbf{b}$ width sizing

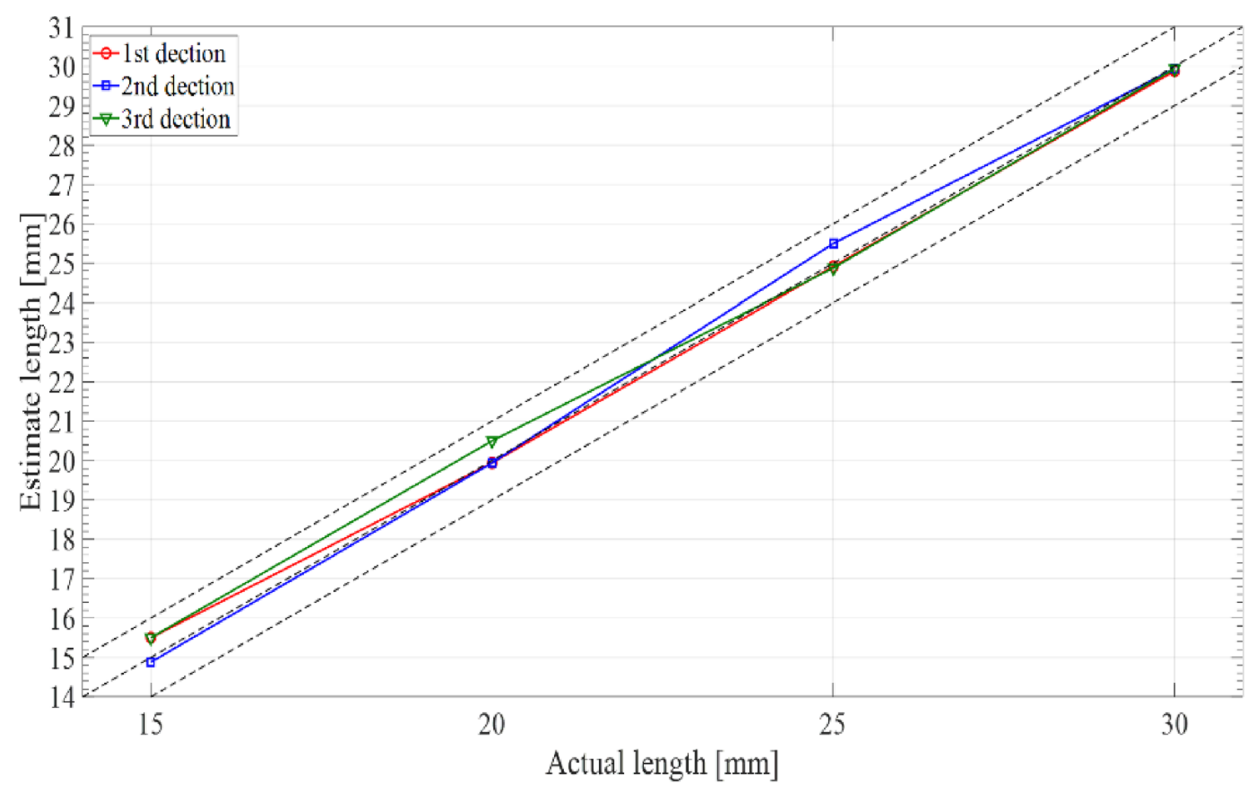

(a)

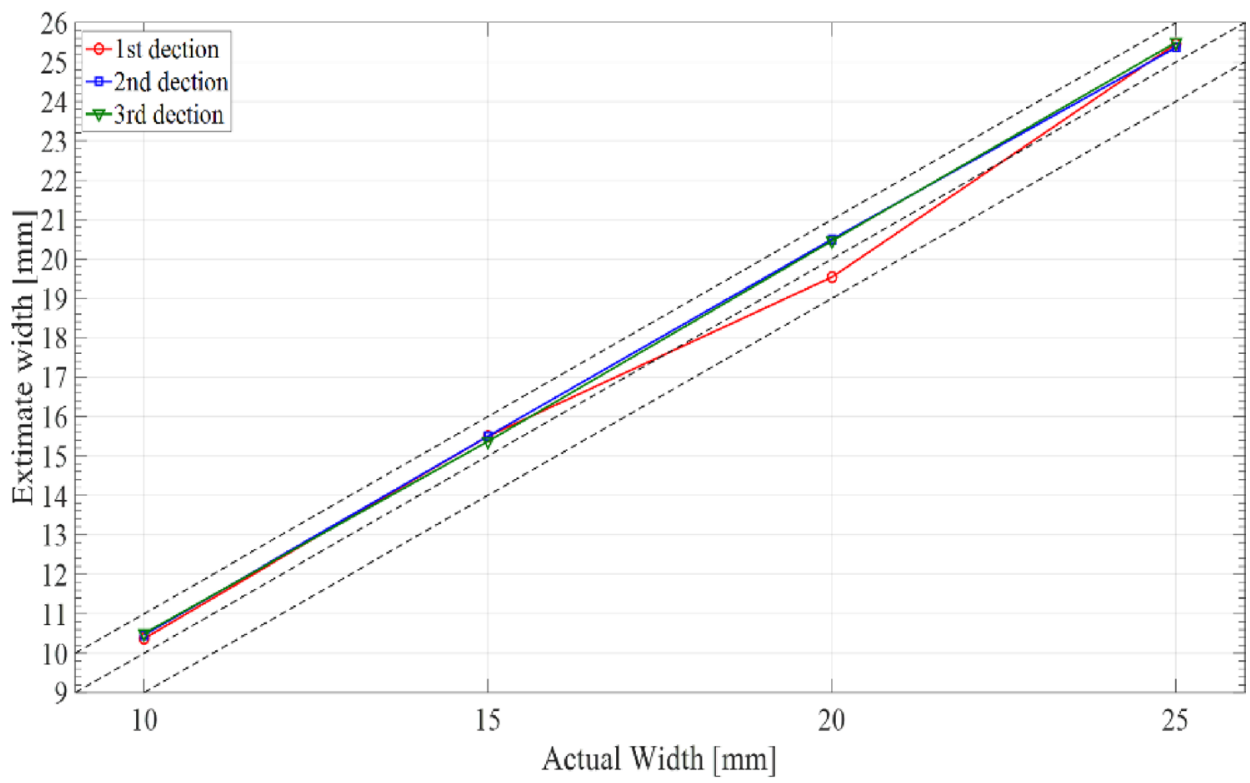

(b) 


\subsubsection{Defect Depth Sizing}

As shown in Fig. 8; Table 2, the average depth sizing results obtained from the three measurements were approximately $1.97,3.92,6.15$, and $7.52 \mathrm{~mm}$, and the maximum errors were approximately +0.01 and $-0.05 \mathrm{~mm}$ for $2 \mathrm{~mm},+0.43$ and $-0.49 \mathrm{~mm}$ for $4 \mathrm{~mm},+0.5$ and $-0.35 \mathrm{~mm}$ for $6 \mathrm{~mm}$, and $-0.86 \mathrm{~mm}$ for $8 \mathrm{~mm}$. Also, the calculated error ranges for the average values were found to increase as the defect depth increased. Therefore, the estimated error range increases due to the decrease in sensitivity as the depth increases, and hence the maximum estimated depth was determined to be $8 \mathrm{~mm}$ for the developed equipment.

\subsection{Natural Defect Sizing}

In order to investigate the field applicability of the developed equipment, three natural defects of varying sizes and shapes caused by operational and environmental factors of trains were comparatively analyzed. The shape of the defect is shelling, and the defect is created by physical factors such as the passing tonnage of the train and environmental factors such as ice and gravel caught between the wheel and rail. The defect depth was measured using the RT method due to the nonuniform condition of the surface and the defect evaluation algorithm of the eddy current inspection equipment was used to obtain the sizing results of the defect size and depth along with the 2D and 3D images. For the shelling defect shown in Fig. 9a, an elliptical shaped piece of the rail broke off and each end of the defect had cracks formed both above and below. The side of the defect was observed to have a semicircular shape, as shown in Fig. 9b, and did not appear to have progressed into an internal defect. The
Table 2 Depth sizing

\begin{tabular}{lllll}
\hline Depth & Actual $[\mathrm{mm}]$ & \multicolumn{3}{l}{ Estimate $[\mathrm{mm}]$} \\
\cline { 3 - 5 } & 1st & 2nd & 3rd \\
\hline 2 & 2.01 & 1.95 & 1.94 \\
4 & 3.82 & 3.51 & 4.43 \\
6 & 6.31 & 5.65 & 6.5 \\
8 & 7.67 & 7.14 & 7.75 \\
\hline
\end{tabular}

approximate size of the defect and its location were ascertained from the 2D image of Fig. 9c; however, it was difficult to distinguish the cracks. The 3D image was obtained as shown in Fig. 9d to accurately identify the shape of the defect where the amplitude revealed that each end of the defect was deep with the lower part being the deepest. The upper crack was not visible but the lower crack was observed through the peak next to the area with the highest peak in the width direction. Table 3 shows a comparison of the actual defect size, RT size, and estimated size obtained from the developed equipment. The actual width of the defect was approximately $30 \mathrm{~mm}$ whereas it was measured as around $29 \mathrm{~mm}$ through the RT method and $27.99 \mathrm{~mm}$ using the eddy current inspection device; for the actual defect length, the RT method resulted in a measurement of around $14 \mathrm{~mm}$, matching the actual length, while the measurement using the eddy current inspection device was around $13.44 \mathrm{~mm}$. For the defect depth, the RT method resulted in a measurement of around $3 \mathrm{~mm}$ and the eddy current inspection device returned a value of around $4.09 \mathrm{~mm}$. Except for the defect width, the error was roughly $+1 \mathrm{~mm}$. Figure 10a shows a shelling defect shaped like a horseshoe, and from the side view image of the defect in Fig. 10b it can be observed that

Fig. 8 Depth sizing

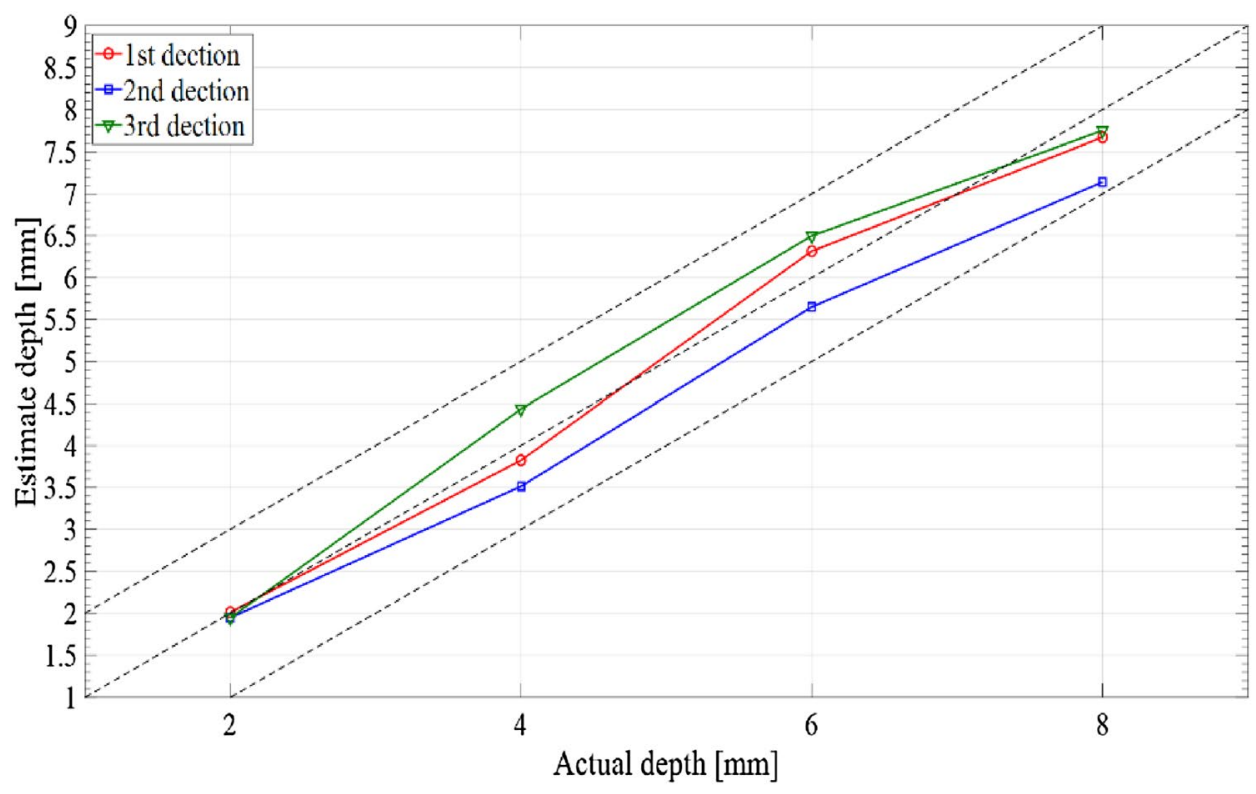




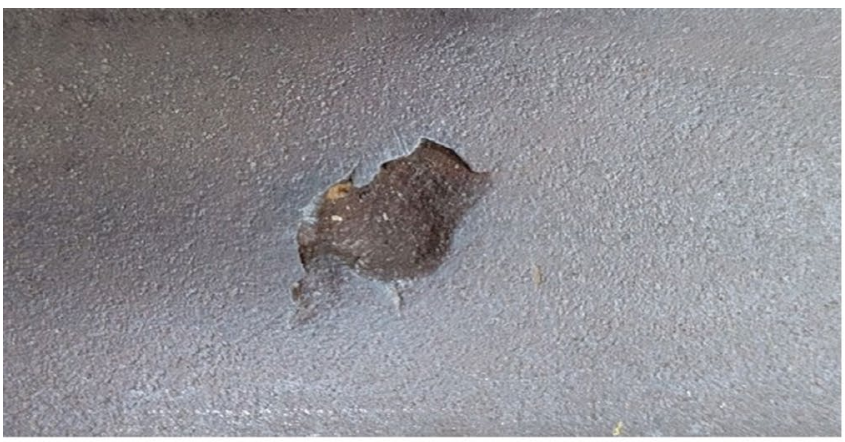

(a)

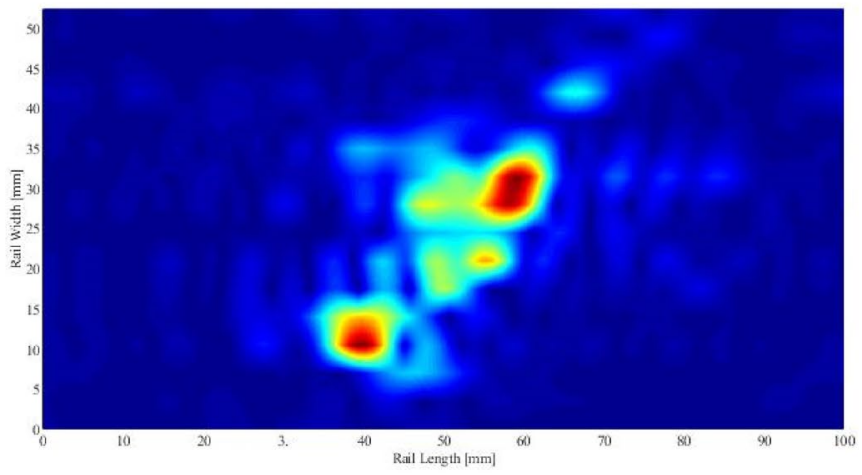

(c)

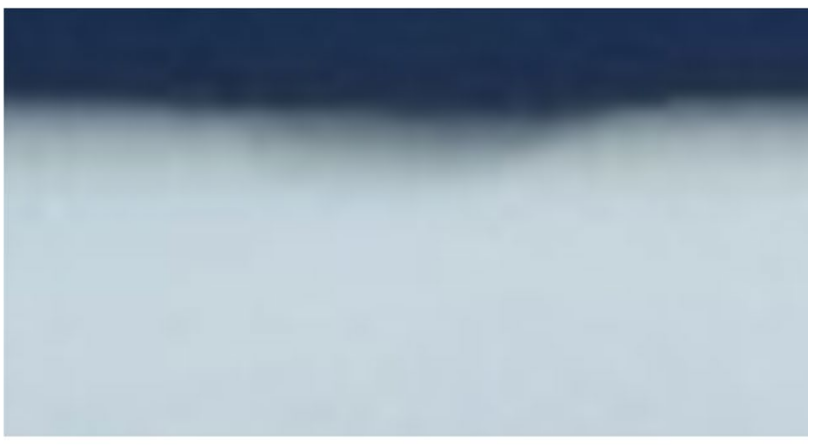

(b)

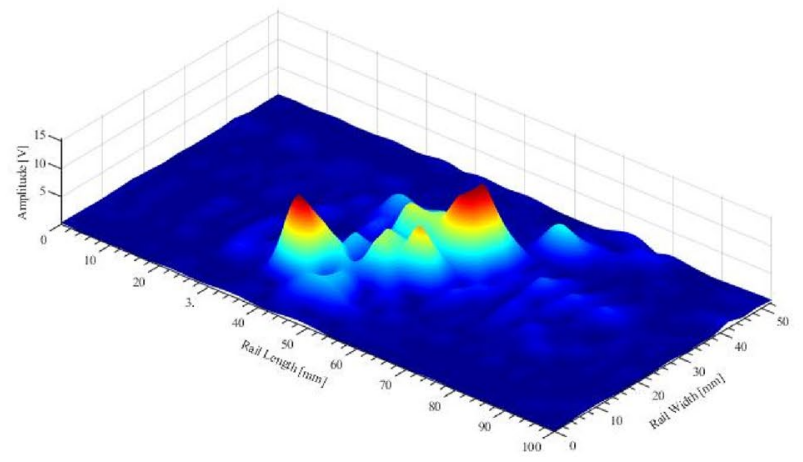

(d)

Fig. 9 Inspection of the first natural defect: a natural defect, b RT image, c 2D image, and d 3D image

Table 3 Comparison of the actual size of the first natural defect with the RT and ECT sizing

\begin{tabular}{llll}
\hline & Width & Length & Depth \\
\hline Actual & 30 & 14 & X \\
RT & 29 & 14 & 3 \\
$\begin{array}{l}\text { ECT detection equip- } \\
\text { ment }\end{array}$ & 27.99 & 13.44 & 4.09 \\
\hline
\end{tabular}

the left side is deeper and trapezoidal in shape. The rough shape and size of the defect could be inferred from the 2D and 3D image of Fig. 10c, $d$ but because it was not similar to the actual shape of the defect, information on the defect through this $2 \mathrm{D}$ and $3 \mathrm{D}$ image was not sufficiently reliable. The reason why the $2 \mathrm{D}$ and $3 \mathrm{D}$ images do not match the actual defect is that the threshold was set so that only defects of $2 \mathrm{~mm}$ or larger can be read in the acquired signal. Therefore, defects with a depth smaller than $2 \mathrm{~mm}$ did not appear in the 2D and 3D images, so they did not match the shape of the actual defect. Table 4 shows the measurement results of the defect size. The RT and eddy current inspection equipment measurements for the length and width of the defect were approximately $1 \mathrm{~mm}$ and $2 \mathrm{~mm}$ greater than the actual measurements, respectively. With regard to the defect depth, the RT measurement was around $3 \mathrm{~mm}$ while the eddy current inspection equipment measurement was around $2.1 \mathrm{~mm}$. The error range of the eddy current inspection equipment was thus measured to be about $\pm 2 \mathrm{~mm}$. Figure 11a shows a shelling defect in the shape of an $\mathrm{X}$ on the rail surface, and the side view of Fig. $11 \mathrm{~b}$ was similar in shape to that of Fig. 10b. The 2D image of Fig. 11c also showed an $\mathrm{X}$ shape, similar to that of the actual defect shape. In addition, it was confirmed that there were additional defects below the defect center. In Fig. 11d, when the depth of the defect is compared, as can be seen from the RT image of Fig. 11b, the amplitude at the bottom of the defect in the left width direction is the highest, so it can be seen that it is deeper than other parts. Comparing the defect length measurement results in relation to the actual defect length in Table 5, the RT measurement was around $22 \mathrm{~mm}$ and the eddy current inspection equipment measurement was around $22.12 \mathrm{~mm}$. For the width, the RT measurement was around $29 \mathrm{~mm}$ and the eddy current inspection equipment measurement was around $28.31 \mathrm{~mm}$. The eddy current inspection equipment measurement was closer to the actual length compared to the RT measurement result. With regard to the defect depth, the RT measurement was about $2 \mathrm{~mm}$ and the eddy current inspection equipment measurement was about $2.57 \mathrm{~mm}$. The measurement results of the eddy current inspection equipment for the three natural defects showed that the error range was largest for the width and the 


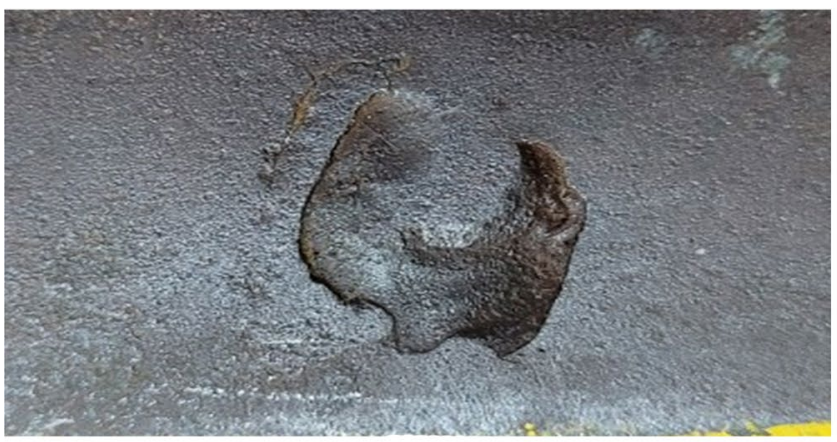

(a)

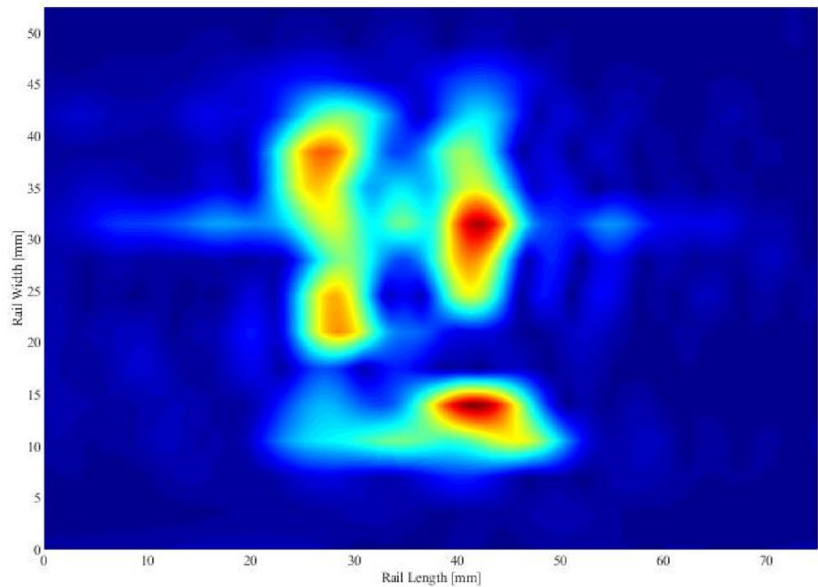

(c)

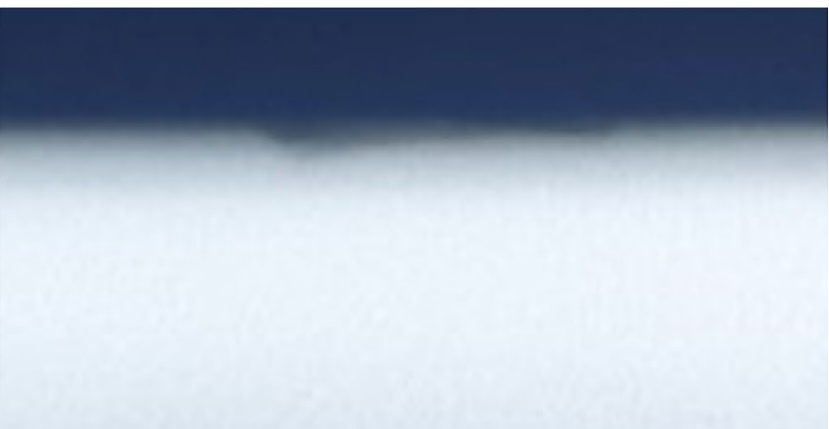

(b)

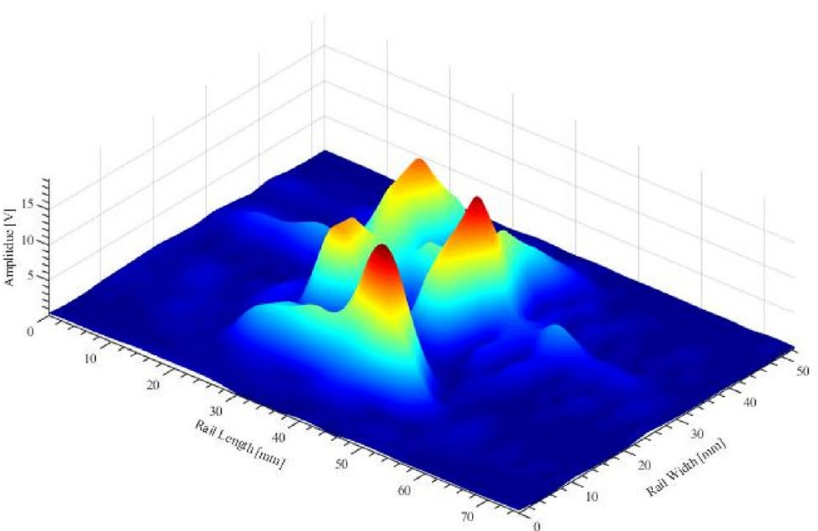

(d)

Fig. 10 Inspection of the second natural defect: a natural defect, b RT image, $\mathbf{c}$ 2D image, and $\mathbf{d}$ 3D image

error range of maximum $+1 \mathrm{~mm}$ and minimum $+0.31 \mathrm{~mm}$ for the length were measured excluding the defect of Fig. 11a. The error range of maximum $+1.09 \mathrm{~mm}$ and minimum $+0.57 \mathrm{~mm}$ was measured for the depth.

\section{Conclusion}

In this study, using the $16 \mathrm{ch}$ eddy current rail defect detection equipment developed by applying the Plus point sensor, finally, the possibility of practical use was confirmed through natural defect detection in the currently using rail. In addition, through the developed defect evaluation

Table 4 Comparison of the actual size of the second natural defect with the RT and ECT sizing

\begin{tabular}{llll}
\hline & Width & Length & Depth \\
\hline Actual & 23 & 18 & X \\
RT & 24 & 19 & 3 \\
$\begin{array}{l}\text { ECT detection equip- } \\
\text { ment }\end{array}$ & 25 & 19.80 & 2.10 \\
\hline
\end{tabular}

algorithm program, the data acquired in the field were analyzed precisely. First, eight defects of varying lengths, widths, and depths shaped similarly to squats were fabricated on rail that was previously in operation, and the inspection results for these defects were shown as 2D and 3D images. The inspection results had the same location and shape as those of the actual artificial defects, and the different lengths, widths, and depths of the actual defects were observed in the inspection results. The error range of the sizing of the length, width, and depth using the defect evaluation algorithm was approximately $\pm 0.5 \mathrm{~mm}$. Therefore, field applicability was shown through the inspection results of artificial defects. Additionally, three defects that occurred on rail in operation were inspected and a comparison of the obtained 2D and 3D images revealed that the defect location and its rough shape and size could be ascertained from the 2D image while the shape and depth of the defect could be determined from the 3D image. Comparison of the actual defect size and the defect size results from the RT method and eddy current inspection equipment showed that measurement of the defect length and width was possible but depth measurement was not possible due to the rough surface, and therefore the RT 


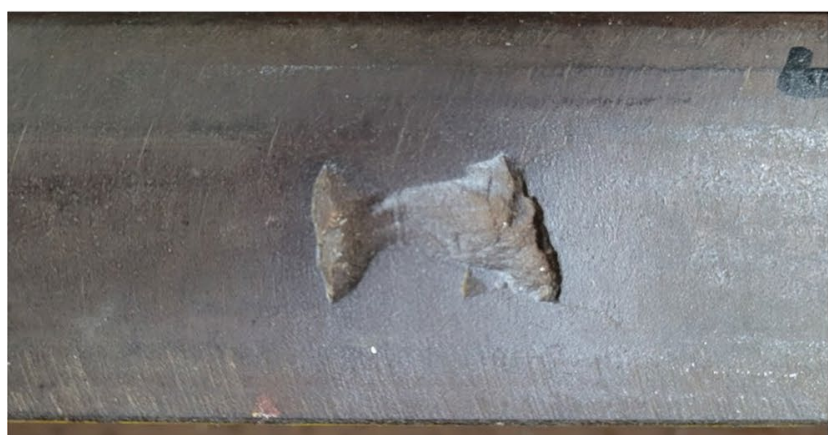

(a)

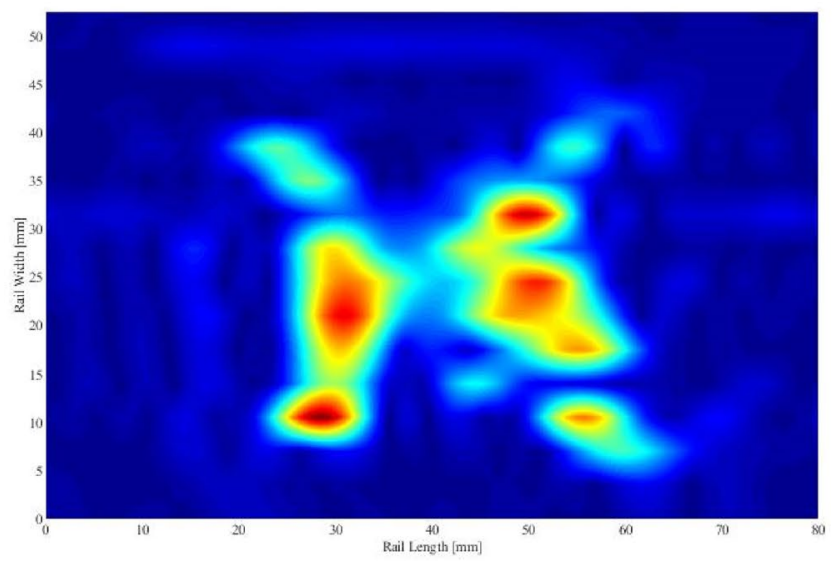

(c)

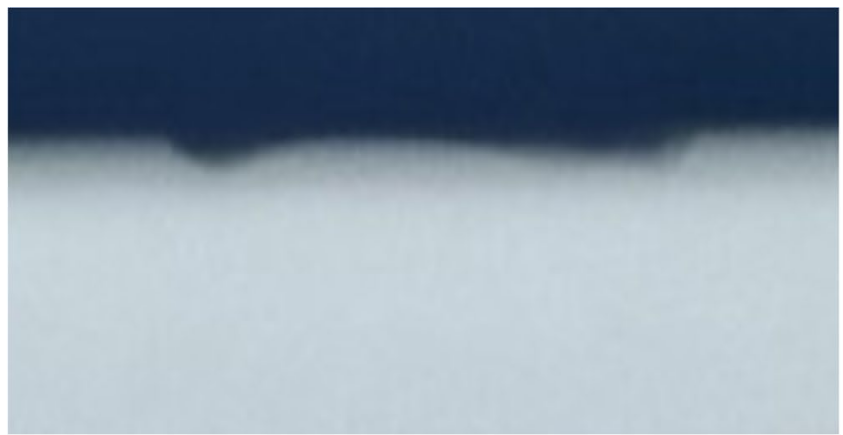

(b)

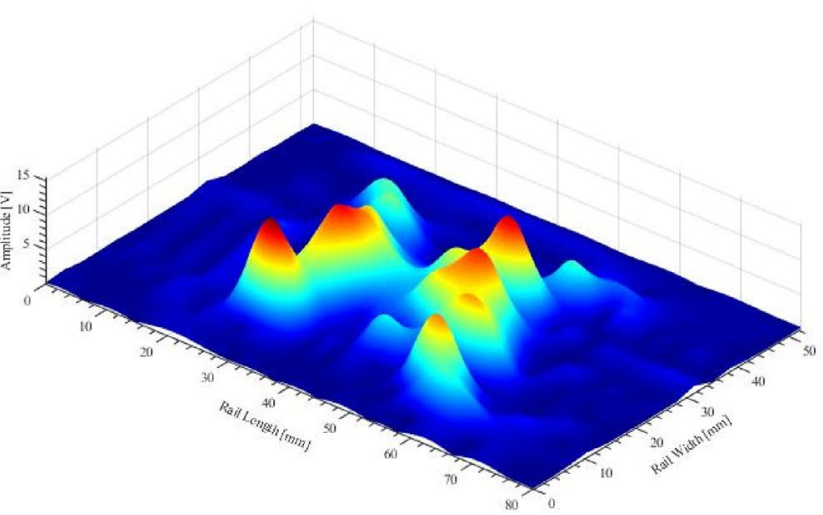

(d)

Fig. 11 Inspection of the third natural defect: a natural defect, b RT image, $\mathbf{c}$ 2D image, and $\mathbf{d}$ 3D image

method results and eddy current inspection equipment results were compared with each other. For the width, the error range of the eddy current inspection equipment was around $+2 \mathrm{~mm}$ excluding the defect of Fig. 11a while the error range was within around $+0.5 \mathrm{~mm}$ excluding the defect of Fig. 10a. For the depth, the error range was at the most around $+1 \mathrm{~mm}$, in contrast to the RT measurement results. The feasibility for practical use was determined using the maximum error range of the defect and the accuracy of the $2 \mathrm{D}$ and $3 \mathrm{D}$ images based on the natural defect inspection results. The developed equipment was developed to avoid dependence on overseas rail defect detection equipment, and it is equipment that prioritizes user convenience through repeated field application experiments.

Table 5 Comparison of the actual size of the third natural defect with the RT and ECT sizing

\begin{tabular}{llll}
\hline & Width & Length & Depth \\
\hline Actual & 22 & 28 & $\mathrm{X}$ \\
RT & 23 & 29 & 2 \\
$\begin{array}{l}\text { ECT detection equip- } \\
\text { ment }\end{array}$ & 22.12 & 28.31 & 2.57 \\
\hline
\end{tabular}

In addition, it is possible to select a replacement cycle for rails and prevent safety accidents by establishing a defect detection D/B through the defect evaluation algorithm program. Further studies will be carried out to improve the inspection accuracy by enhancement of the resolution and error ranges of the $2 \mathrm{D}$ and $3 \mathrm{D}$ images.

Acknowledgements This research was carried out with the support of the project development of Development of essential equipments and devices required to install the CWR on the existing ballastless track structure (Research No. 20RTRP-B138006-04) supported by the Korea Agency for Infrastructure Technology Advancement (KAIA)

Open Access This article is licensed under a Creative Commons Attribution 4.0 International License, which permits use, sharing, adaptation, distribution and reproduction in any medium or format, as long as you give appropriate credit to the original author(s) and the source, provide a link to the Creative Commons licence, and indicate if changes were made. The images or other third party material in this article are included in the article's Creative Commons licence, unless indicated otherwise in a credit line to the material. If material is not included in the article's Creative Commons licence and your intended use is not permitted by statutory regulation or exceeds the permitted use, you will need to obtain permission directly from the copyright holder. To view a copy of this licence, visit http://creativecommons.org/licenses/by/4.0/. 


\section{References}

1. KRRI: Construction Rule and Regulation on Korean Railroad' Report. KRRI, Uiwang-Si (2017)

2. Han, S.W., Cho, S.H.: Review of non-destructive evaluation technologies for rail inspection. J. Korean Soc. Nondestruct. Test. 31(4), 398-413 (2011)

3. Papaelias, M.P., Roberts, C., Davis, C.L.: A review on nondestructive evaluation of rails: State-of-the-art and fu-ture development. Proc. Inst. Mech. Eng. Part F: J. Rail Rapid Transit 222(4), 367-384 (2008)

4. Kabir, S., Alsulami, B.: Assessment and monitoring for railway tracks reliability and safety using nondestructive testing measurement systems. Int. J. Railw. Res. 2, 24-32 (2015)

5. Kishore, M.B., Park, J.W., Song, S.J., Kim, H.J., Kwon, S.G.: Characterization of defects on rail surface using eddy current technique. JMST 33(9), 4209-4215 (2019)

6. Cannon, D.F., Edel, K.O., Grassie, S.L., Sawley, K.: Rail defects: an overview. Fatigue Fract. Eng. Mater. Struct. 26(10), 865-886 (2003)

7. NSW Transport RailCorp: Rail Defects Handbook: TMC 226, pp. 1-83. NSW Transport RailCorp, Sydney (2012)

8. Deutschl, E., et al.: Defect detection on rail surfaces by a vi-sion based system. In: IEEE Intelligent Vehicles Symposium, pp. 507-511. IEEE, Parma (2004)

9. Szugs, T. et al.: Combination of ultrasonic and eddy current testing with imaging for characterization of rolling con-tact fatigue. In: 19th World Conference on Non Destructive Testing, pp. 1-8 (2016)

10. Dey, A., Kurz, J., Tenczynski, L.: Detection and evaluation of rail defects with non- destructive testing methods. In: 19th World Conference on Non Destructive Testing, pp. 1-9 (2016)
11. Park, J.W., Park, J.H., Song, S.J., Kishore, M.B., Kwon, S.G., Kim, H.J.: Enhanced detection of defects using GMR sensor based remote field eddy current technique. J. Magnet. 22(4), 531-538 (2017)

12. Park, J.W., Park, J.H., Song, S.J., Kim, H.J., Kwon, S.G.: GMR sensor applicability to remote field eddy current defect signal detection in a ferromagnetic pipe. J. Korean Soc. Nondestruct. Test. 36(6), 483-489 (2016)

13. Garcia-Martin, J., Gomez-Gil, J., Vazquez-Sanchez, E.: Nondestructive techniques based on eddy current testing. Sensors 11(3), 2525-2565 (2011)

14. Lee, T.G., Yeom, Y.T., Kim, H.J., Song, S.J., Kwon, S.G., Kwon, S.D.: Analysis of eddy current signal of defects on railway. Korean Phys. Soc. 69(4), 361-368 (2019)

15. Lee, H.-J., Kim, Y.-S., Nam, M.-W., Yoon, B.-S., Kim, S.-K.: Eddy current testing of weldment by plus $(+)$ point probe. J. Korean Soc. Nondestruct. Test. 19(6), 426-432 (1999)

16. Sabbagh, H.A., Sabbagh, E.H., Kim Murphy, R.: Recent advances in modeling eddy-current probes. In: AIP Conference Proceedings. American Institute of Physics, College Park (2002)

17. Dwyer-Joyce, R.S., Lewis, R., Gao, N., Grieve, D.G.: Wear and fatigue of railway track caused by contamination, sanding and surface damage. In: $6^{\text {th }}$ International Conference on Contact Mechanics and Wear of Rail/Sheel systems, pp. 211-220 (2003)

Publisher's Note Springer Nature remains neutral with regard to jurisdictional claims in published maps and institutional affiliations. 